\title{
Narrating National Geo Information Infrastructures: Balancing Infrastructure and Innovation
}

\author{
Henk Koerten $^{1}$, Marcel Veenswijk ${ }^{2}$ \\ ${ }^{1}$ Department of Delft University of Technology, Amsterdam, Netherlands; ${ }^{2}$ Department of Culture, Organization and Management, \\ VU University Amsterdam, Amsterdam, Netherlands. \\ Email: h.koerten@tudelft.nl, m.veenswijk@fsw.vu.nl
}

Received September 10, 2009; revised October 16, 2009; accepted November 18, 2009.

\begin{abstract}
This paper examines narratives relating to the development of National Geo Information Infrastructures (NGII) in ethnographic research on a Dutch NGII project which was monitored throughout its course. We used an approach which focuses on narratives concerning the environment, groups and practice to elicit sense-making processes. We assert that narratives are relatively fixed and that they only change under specific circumstances. Moreover, the fixing of or change in narratives takes place in practice, so our research approach aimed at analysing narratives of practice, which we label 'storyboards'. For this purpose, project meetings and conferences were observed, key persons both within and outside the project environment were interviewed, and an analysis of relevant documents and video footage was undertaken. Storyboards are created by actors as a result of day-to-day challenges related to project goals, technology and infrastructure. In our research we found that these storyboards occur as vicious circles from which actors cannot escape. In the specific case analysed, our interpretation of the narrative storyboards suggested that these vicious circles are caused by the inability of project participants to distinguish between infrastructure and innovation requirements in their daily work.
\end{abstract}

Keywords: Narrative Analysis, Narrative Approach, Innovation, Organisation, NGII, Infrastructure

\section{Introduction}

There is a worldwide tendency to create facilities on a national scale to collect and disseminate location-based information, usually called geo information [1]. Car navigation systems are a form of geo information used by the general public, and geo information is also applied in government and business organisations to make them more effective. Within organisations, this information is often managed by a Geographical Information System (GIS), and between organisations, through National Geo Information Infrastructures (NGIIs) with national governments playing a key role in their dissemination [2-5].

When setting up a program aimed at establishing NGIIs, policy advisors take organisational aspects seriously, but do not treat them as manageable phenomena [6,7]. Technical aspects are regarded as crucial [3], and those involved in implementing the programs generally seem to overlook the organisational consequences, denying the relationship between organisational change and NGII implementation [8]. Therefore, organisational structures, modes of cooperation and work relationships have not been topics of interest in the context of research into NGII implementation [9].

However, while technological developments are still regarded as crucial, those involved in implementation are now more inclined to take the organisational aspects of NGII development into account, culminating in design rules borrowed from political science, economics and management science [10-12]. Practitioners still point to difficulties with infrastructure development-mostly in the context of specific projects-of which we still have little knowledge of the lived experience of the project members [13,14].

Our aim is to find out why people who have problems in their daily work nevertheless maintain their current practices and refrain from looking for alternative methods. In relation to NGII development, there is a tendency to continue developing design rules while rarely taking the implementation processes into account. Our focus is practical: on how NGIIs are discussed in meetings, interviews and policy documents, where these discussions culminate in the creation of narratives. The research question guiding this paper is: How can we understand NGII 
implementation using narrative analysis? Our secondary questions are: How do technological and organisational aspects interact with each other? How are goals and results perceived? And do these goals and results change over the course of the project?

Using a narrative approach, this paper provides an indepth ethnographic case study of a Dutch NGII implementation project called Geo Portals. The project was intended to realise a part of the Dutch NGII by disclosing governmental geo information in a thematically organised way. Our research findings demonstrate that the initial project goal of building an infrastructure gradually changed over the course of the project, moving towards knowledge creation to facilitate innovation aimed at the further development of the NGII.

We will start with a description of the theoretical assumptions underlying the narrative analysis approach to research, followed by an account of the research methodology. An analysis of the project in terms of the theory will follow, and finally, we will provide a summary and some concluding remarks.

\section{The Narrative Analysis Approach to Research}

Symbolic interactionism introduced the idea that human thought is shaped by social interaction, and treated the modification of meanings and symbols as a process [15]. Goffman expanded this notion by adding the ability of human beings to look at themselves from another point of view [16], framing the notion using the theatrical terms of a 'front-stage' and a 'back-stage' [17]. Over his career, Goffman became aware of the ritualistic and institutionalising aspects of social interaction, but failed to specify how and why these frames or structures emerge [18-20].

Sociologists have attempted to understand society by gaining insight into how the structures involved in the process of modernisation affect our lives [21-24]. Some have made efforts to integrate micro and macro approaches [25-27]. For example, Bourdieu implicitly rejected the assumption of an objective truth, implying that structures are socially constructed, and he attempted to take a middle position which he labelled both 'constructivist structuralism' and 'structuralist constructivism' [27,28]. Bourdieu conceptualised habitus as the cognitive structures through which people deal with the social world, being both individual and collective, dialectically developed and internalised, a process which he labelled 'practice'. A 'field' was conceptualised as a network of relations among objective positions and not as a network of interactions or inter-subjective ties among individuals. These relationships, regarded as existing externally with respect to individuals, determined the position of individual agents through their acquisition of various kinds of capital: economic, cultural (knowledge), social (rela tionships) and symbolic (prestige). In this process, field and habitus define each other in a dialectical relationship.
Bourdieu and Goffman may have different points of departure, but there are similarities in their conceptualisations. Goffman's dramaturgical perspective may, to a considerable extent, be comparable to Bourdieu's habitus, while Goffman's notion of frames resembles Bourdieu's field concept and practice is more or less interchangeable with Goffman's concept of the 'front-stage'. While this comparison may appear to be a broad generalisation, these observations will prove useful in blending the two approaches together into one theoretical concept for research. Nevertheless, while an intersectional framework such as this might provide useful notions about the life world affecting individual, group and inter-group behaviour, the very aspect of meaning creation remains unaddressed. It remains unclear how images come to life and develop over time, as this framework assumes univocality, iniquitousness and fully informed actors and as such the ambivalence, ambiguity and incompleteness of worldviews is overlooked.

Thus, the theoretical notions presented above provide useful hints for a theoretical approach but do not address the process of sense-making needed to answer the research question. Therefore, we will focus on the interpretation of lived experience as a guide for action and extend this towards a narrative approach using linguistic, anthropological and social psychological insights [29-31]. Interpretation, meaning creation and sense-making have become guiding concepts in the development of less positivistic methods [32,33]. Two sources that have inspired narrative theory may be distinguished: a 'linguistic turn', inspired by Saussure, Wittgenstein, Chomsky and Derrida, and a 'narrative turn', with more emphasis on stories and meaning, represented by authors such as Barthes, Bakhtin, Boje, and Gabriel [34].

In itself, language has no relationship to time or the originator of an utterance [35]. The concept of discourse, however, is treated as a combination of spoken word and written text, linked to time and space and used to make sense of the world, without drawing a distinction between the two [36]. In relation to the concept of discourse, the process of enactment is conceived of as communication through written and spoken symbols, usually linguistic. For example, to complete a management task, people write, read, speak, listen and discuss, using messages which convey myths, sagas, results, setbacks, challenges or strategies [37].

While language has been recognised as the dominant vehicle for the development of meaning in the discursive approach, the dynamic character of organisational practice has invoked interest in linguistic aspects other than text alone, such as metaphor, stories, novels, rituals, rhetoric, language games, drama, conversations, emotions and sensemaking [38]. Grounded in literary criticism, new methods of analysis have emerged and been labelled as the narrative turn, which is aimed at delineating stories and storylines rather than texts [39-42]. 
Meaning is created, maintained, altered and destroyed and may be used to contemplate, to manipulate, be purposeful and invoke change [43-47]. The narrative turn has been considered fundamental in interpretive organisational research for conceptualising the notion of organisation in a more dynamic way (Hatch and Yanow, 2003). These dynamics have been envisioned in terms of people using and producing frames of reference in a cyclical process of enactment-selection-retention [48], as a dialectical process moving towards objectification [28], or as a narrative that is edited under particular circumstances [31,49]. The concept of narrative is broad, in the sense that it can be regarded as structuring human memory, and therefore should be conceptualised as both medium and process [50]. The concept of discourse, however, is more defined, referring to meaning produced in the exchange of signs and symbols, and in this respect more closely related to symbolic interactionism [50,51].

Narrative has been regarded as story [42], as telling a story [38] and as the art of telling a story [52], while there are also other approaches concerned with linking stories and narratives [49,53-55]. Living in a world composed of stories, we use narratives for communication and to give meaning to experience [42]. In providing an account of events, narratives allow us to create an interpretation of these events, relating the story in a favourable manner. Some stories are created for single use, while others are retold and altered and in the process gain a meaning they would never have had if they had been told only once. In this way they become a frame of reference for future stories and actions [56]. Once stories begin to have a life of their own, they grow further to become narratives which might be only loosely or even poorly connected to the original [55]. They become universal images, constituting all aspects of society, referring to the culture of all kinds of people, culminating in identity-creation using social categories [57]. From a manager to a company car, human and non-human identities are created by storytelling, leading to narratives that are continuously constructed and therefore subject to change. Having a plot does not imply that narratives are always visible and recognisable, they can be prominent or latent, and can also sometimes be unconsciously present to actors. They are an interpretation of assembled, either real or imagined stories, which Boje, after Clair, called 'narratives dressed as theories' [55].

The hermeneutic approach implies that a specific narrative can only be understood when it is interpreted in relation to other narratives, for example if we conceptualise narration as a 'grand narrative' grounded in many 'micro stories' which are mutually dependent $[49,55]$. This notion is reminiscent of the sociological micro- macro debate which links Bourdieu to the insights presented above. To avoid being confined to a type of hierarchically layered concept, one can focus on the morphology of narra- tives over time, conceptualising how such narratives are edited by the actors involved so as to invoke the narrative, as well as sustain or to change it $[31,49]$. However, because the editing process is associated with the particular editors, there is a danger of overemphasising the role of individuals and in so doing implicitly sustain the idea of 'culture creation' or 'cultural intervention', which we have seen before $[43,58]$.

The notion of narrative has also been distinguished by declaring everything before narrative to be 'ante-narrative'. Verduijn refers to ante-narrative as 'lived experience', which she finds to be speculative, multifaceted and ambiguous, and while it always tends towards a coherent story, it is always prior to its reification into a sensible narrative [30,34,55]. However, while this distinction may be tempting, it is difficult to sustain the division between narrative and ante-narrative. This approach also presupposes that all the storylines-the 'Tamara of stories'-can be known by the researcher [30]. However, it is impossible to grasp the full picture, just as it is impossible to simultaneously be in all places at all times. Nonetheless, people still look for a clear, overall picture to give sense to their experiences, and therefore missing elements are filled in and the incomplete picture is supplemented with fantasies that function as experiences and thus construct the full picture [35,50]. Thus, the development of meaning requires an overall understanding of the relevant situation, in terms of both ante-narrative and narrative.

As humans, we can only understand change with great difficulty, we notice when something has changed only after a certain period of time has elapsed and we perceive this as an interval [59]. As a result, change is reduced to a series of instances: the difference between one state of affairs and another gives us clues about change, determining our thinking about time in a profound way [60,61]. Due to modernity dictating a linear concept of time, we tend to experience that as 'concrete lived time' [62], and while change is basic to life, it is difficult for humanity to grasp it. In this sense, we are 'becoming' instead of 'being' $[60,63,64]$. The concept of becoming elicits the sense we make of change. Sense-making, or meaning creation, can be envisioned as a human attempt to comprehend change, in a process in which we attempt to convert an influx of stimuli into adequate concepts [62]. However, striving for fixed concepts in the process of sense-making means that intentional shifts in meaning rarely occur because of the tendency to maintain familiar concepts. Despite this tendency, meaning does change-usually without the awareness of the meaning creator-due to the changing environment. The propensity to ignore change by creating stable narratives is prevented by these changing circumstances, giving change the quality of 'basic assumption' or a 'deep structure' [65], or of basic, dichotomous, generally subconscious human preferences [66]. For Schein, the more superficial cultural notions are, the more they are subject to change, in which case perhaps it would be better to 
describe both superficial and deep structures as changing, but with the latter not being narrated as such.

\subsection{A Narrative Framework for Research}

As the outcome of sense-making processes, narratives are dynamic. How narratives come into being and how existing narratives enhance or constrain new narratives, creating relative stability or a momentum towards change, will be conceptualised within this framework [67]. We will discern narrative conceptualisations about scene, actors and actions, in terms of narrative setting, narrative space and narrative storyboard respectively (see Figure 1) [40,68]. A narrative setting concerns notions about the narrated environment. Narrative spaces refer to configurations of actors and how they interact with each other and narrate their world, individually and collectively. Narrative storyboards arise from reflection on practices and are transposed into relatively fixed patterns, which can be regarded as the outcome of the propensity of human beings to consider sense-making itself in terms of fixed concepts [62].

The narrative setting conceptualises narratives about the environment, time and space. The notions of local and global, presence and absence and home and abroad are combined in the narrative setting, and images of the technological environment are also found here. Notions about change, stability and institutionalisation come together in an enacted location, which is to say, a locus where narratives combine $[66,69,70]$. People act in different ways, within different groups, within a specific narrated setting, acting in a local or global manner and in an explicit or implicit way. They create narratives about that specific location at that specific moment using images from the past, present and future, from the local community to the global environment. It is their lived experience of that location which is narrated.

The narrative setting also refers to the physical environment, which includes buildings [71,72]. Gastelaars analysed a building as a site, space or skin, and as a place to be [73]. She refers to the theatre, using the metaphor developed by Burke and Goffman in their notions of a

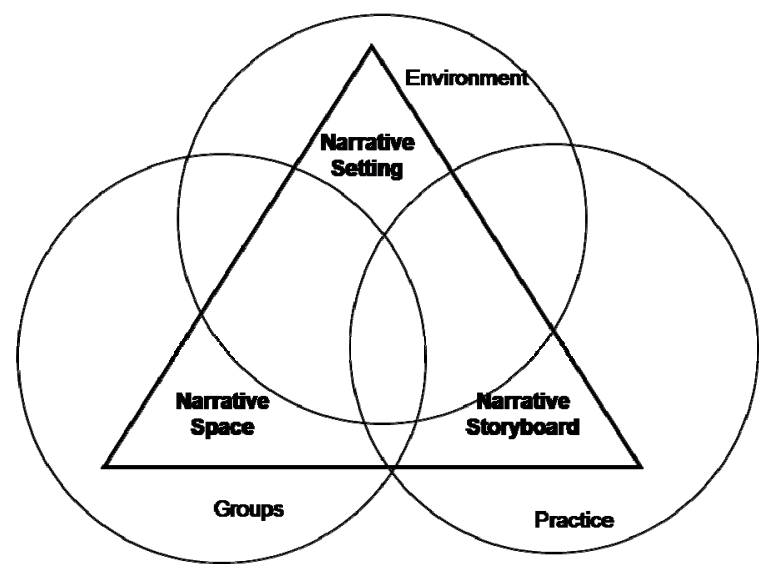

Figure 1. Theoretical focus front-stage, an offstage or backstage, and the wider environment $[17,40]$, making us aware that physical locations may have different functions in different contexts: in one situation the location may be considered to be frontstage, while in another it may be backstage or reflect an even wider environment. The presence of props and the 'personal front' of people, realised through physical objects, also needs to be mentioned in this context.

Thus, the narrative setting has tangible and non-tangible aspects $[48,69,74]$. An intangible software program used through a tangible computer is an example of a complex relationship which has a fundamental impact on how things are done [75]. Bijker has suggested that technology is shaped through images of how it will be used, being conceived in subjective, partial and distorted images $[76,77]$. The narrative setting enacts how technology in the lived environment is linked to time and space [60]. It is a relatively stable image of the environment, however vulnerable to redefinitions. Only when they become untenable, will narratives about the setting explicitly or tacitly change, influenced by narratives about the past, present and future.

One or more narrative spaces may be discerned within a narrative setting. They represent groups of people and are therefore the link to human existence. They might enact a department, organisation, profession, religion or subgroup. The interplay of narrative spaces might invoke action or conversely create a deadlock or cease-fire. Narrative spaces are ever-changing kinds of 'zoning plans' for enacted human groups, determining their nature and limits, and they may form quite complex combinations, as human thought is very capable of generating and handling these complexities. They do not necessarily have links to or comply with organisational or societal structures $[45,66,78]$. Governed by a search for predictability, narrative spaces appear to represent stability, enacting cultural entities to create a stable environment. However, narrative spaces are also vulnerable to change, as they must adjust to new developments, which are usually conceptualised as changeable, moving from one form of stability to another [79-81]. Thus, a narrative space is enacted as stable, offering a comfort zone, an image which invokes predictability, but also a path to follow, towards an enacted, desired state of affairs. Narrative spaces allow people to know what to do, who to trust and where to go. They make clear what is important and what is not, what is consonant or dissonant, and ultimately they indicate how to progress to another stage. While experienced as stable, narrative spaces are consciously and unconsciously changing.

Narrative storyboards are the bedrock of human actions, providing predefined scripts. In a world that is made up of a constant flow of events we enact that world as stable and predictable, while also requiring fixed recipes for action. Heavily anchored in narratives on the envi- 
ronment and social groups, they are also based on past and future actions $[28,48,59]$. People adhere to certain unwritten rules in daily life, allowing them to present themselves as good citizens, and thus feel uncomfortable when the rules are not appropriately applied [82]. Storyboards provide us with a narrative of how to move from an initial state of affairs towards a new state within a particular context. They may relate to action that still needs to take place, that which is being undergone, or that which has already taken place, linking the action in question to time and space and thereby delimiting the storyboard's explanatory power. In this way a plot of the action is provided and related to the circumstances conceptualised in narrative settings and narrative spaces [17].

Storyboards emerge in relation to groups of people, who can be considered as apprentices becoming accustomed to a general way of doing something [83]. The people within such a group may feel confined in relation to a specific array of actions which have been proposed as a means to move from chaos to order [84]. Predictions concerning actions and outcomes are made because these allow people to know what to expect and to determine which stories are dominant and how they form a logical sequence [53]. The narrative storyboard makes us aware of the limited ways of creating a plot. It reveals how a specific storyboard connects to the setting and spaces of its constitutive narrative and what aspects of the narratives are specific to that storyboard. Their predictable features make them triggers for change. In this way, while the exact prediction of narrative progression is impossible, the narrative provides building blocks for the analysis of change, shedding light on how narrative change can be mapped [30].

\section{Methods}

This section will provide some information on the context of the Geo Portals project, as well as an explanation of the ethnographic research design.

\subsection{Context}

In early 2005, the National Initiative for Innovation Stimulation (BSIK) began the Space for Geo Information program (SGI) (Ruimte voor Geoinformatie). The project ran until the end of 2008, with a budget of 58 million euros. The SGI program was set up to provide grants to projects dealing with geo information and thereby stimulate innovation and promote the realisation of the Dutch National Geo Information Infrastructure (NGII). The Geo Portals project emerged from the initial discussions on the content and design of the SGI program, bringing together thirteen governmental and non-governmental organisations in the field of geo information who proposed the establishment of a network of geo portals for the disclosure of geo data. The Geo Portals project had a two million Euro budget, with 60 percent of its funding com- ing from the SGI initiative, while the participating organisations were to supply the remaining 40 percent. Within the Geo Portals project, geo data was regarded as a crude product that should be thematically disclosed in order to obtain geo information from which society as a whole could benefit.

In relation to the multifaceted palette of the SGI program, Geo Portals was one of the larger projects, and was often described as a prestigious, key project by program officials. The projects that were set up were evaluated in terms of their ability to bring the Dutch NGII closer to completion. In this context, Geo Portals was focused on the overarching goal of the program: disclosing geo data from different sources to produce geo information.

\subsection{Research Design}

In the next section, we will present ethnography of the Geo Portals project, which ran from the beginning of 2005 until the end of 2008. It will become clear that narratives referring to the project changed during its progression. However, before turning to the case description we will explain the ethnographic design of our research.

One researcher monitored the project during its course. Because social scientific research on how the project was conducted was one of the project goals, the researcher was accepted as a full member of the project committee, which consisted of one representative from every participating organisation. Monthly meetings were scheduled with the intention of addressing management issues and, especially at the outset, serving as a platform for developing the scope of the project. Workshops open to and aimed at professionals within the geo information sector were also organised with the purpose of project promotion. Two brainstorming sessions were held by the project team in the first phase of the project, intending to establish a clear and univocal project approach agreed on by the project committee. These events were observed and also interviews were conducted with key persons, both during the commencement and conclusion phases of the project. Relevant documents and some video footage were also analysed. In addition, the researchers observed the presentations of the project at the geo information conferences, as well as the subsequent audience reactions.

Ethnographers have to be convincingly authentic ('been there'), plausible (relevant to the reader) and engage in critical analysis [85]. In order to do so, this research project followed writing conventions developed by Watson and extended by Duijnhoven concerning the transfer of field notes into convincing and authentic texts [86,87]. To meet these requirements, we will present excerpts from our interviews and field notes. In order to summarise the numerous discussions occurring during meetings, these have been condensed into a representation of the typical form of the discussion concerning a particular 
topic. These representations of conversations are in essence fictitious; however, they are based on conversations recorded in field notes and, to a lesser extent, in interviews.

The research materials revealed the presence of narratives that developed over time. They were in continuous flux and either prominent or concealed, close or distant. The narratives within the project not only show how projects function as arenas where the narrative of change is created, contested, appropriated and diffused, but also how the quest for project narratives among members may serve both to reduce as well as to increase ambiguity. On the one hand, the project narratives seem to reduce ambiguity by providing a 'narrative of change' in terms of the use of new software applications. On the other hand, these software applications fail to offer a solution because they create a new ambiguous situation, requiring another 'narrative of change'. Coping strategies are developed through the redefinition of the initial project goals, aligning them to these narratives of change.

\section{Analysis}

In this section we provide a detailed description of three phases of the Geo Portals project. Each is described separately and followed by a narrative analysis that identifies the narrative setting, space and storyboard.

\subsection{Getting Started}

The SGI program started in 2002, with the basic idea of stimulating innovation in order to boost geo information sharing. The next step was to bring together representatives of organisations in the GI field to make goals more concrete. The result was a glossy brochure, with a program outline produced by a consortium of 10 universities, 20 research institutes, 60 companies, 40 governmental bodies and 30 geo information producers [88]. It was argued that government needed complex information about a complex society to develop convincing policies. To make the information manageable, it was to be ordered spatially as geo information, disclosed by a National Geo Information Infrastructure (NGII). The bottom line was to make geo information available in a structured manner, with it being disseminated independently by individual organisations.

To promote future projects, SGI organised 'broking and bargaining days' on which representatives of organisations from the GI sector were invited to generate project ideas. It was in this context that the concept of Geo Portals emerged. Some typical observations of those in attendance were as follows:

SGI mobilised the field. They organised broking and bargaining days in order to get rough ideas. Some 25 ideas were identified as potentially successful. In the end, these ideas were connected to organisations; it was just one big dating show. It became obvious that some central portal facility was needed and that our organisation should play a role in its development.
I remember how Geo Portals emerged. The idea behind broking and bargaining events organised by SGI was that through discussion among representatives of geo information organisations, ideas for concrete projects would pop up. During one of those meetings, the Geo Portals concept just came out of a plenary discussion. Then the moderator asked which organisations were willing to participate. Representatives of interested organisations raised their hands, as did I. So, all of a sudden I was an initiating member of an instantly formed club of enthusiastic people who wanted to disclose geo information through portals.

That the overarching concept of Geo Portals should be liberty united, was obvious from the outset. A central, topdown organisation was totally out of the question. The idea was a network of portals of different nature, working together with a minimum set of rules.

Those involved in the discussion saw the rudimentary concept of Geo Portals as a collective idea in need of development. The thirty organisations willing to participate were gradually reduced to thirteen, and in October 2002, representatives from these organisations presented an initial proposal which envisioned thematically categorised, colour-coded portals like red for built environment, green for nature and agriculture, and brown for subsurface conditions [89].

After the initial submission in 2002, a rewriting process occurred, giving the project more focus. In the minutes of early project meetings, there are clear conceptions about how data should be distributed. It was stated that all the processes for disclosure, search, diffusion and payment should be web-based, while how all the different data sources were to be connected was not a matter of discussion. The first rudimentary description of the geo portal framework presented a static image: the portal would be based on proven technology and standards and also on a fixed notion of architecture [90].

While the project goals were stated clearly and unambiguously, at their regular meetings the representatives of the participating organisations expressed doubts about how to proceed. They were uncertain about the financing and procedures for reporting to SGI, but even more about the essence of the project. Now the project was about to start, the representatives felt the need for definitions about what a portal should look like, how users would be reached and what technology would be used in its setup. A typical discussion in a meeting of representatives would proceed as follows:

A: If we want to set up a proper Geo Portals, we need to be clear about standards. It is obvious that we use the most recent and commonly used standards. We are not going to use any standard that has not been accepted by the community, or that has not proved to be useful.

B: I agree on that. If nobody objects, we should proceed to the next topic, and that is user orientation. We have to be demand-driven, preventing us from making the same mistakes they made in the NCGI project. So how can we be demand-driven? 
$\mathrm{C}$ : First and foremost we need to disclose our data in a way that it can be readily found. Furthermore, we need to present it in a format that can be read by the user. So, we need to use the proper standards.

B: I agree. We need to use proper standards, those that are widely accepted.

A: Now we agreed on how to settle the standards issue, we are discussing standards again.

The motto of Geo Portals was 'liberty united', which reflected the fact that it was a network of portals established by various organisations, each with its own autonomy, but working according to a minimal set of rules. In defending this view of the essence of Geo Portals, it was often explained as a reaction to a former national project regarding geo information, the National Clearinghouse for Geo Information (NCGI). The feeling was that NCGI had failed due to the central, top-down enforcement of detailed standards and work procedures and this had proved to Geo Portal protagonists that organisations were not inclined to comply voluntarily with strict rules. To avoid another failure, they decided to meet as a small group of motivated organisations connected through a minimal number of mutually agreed standards.

While Geo Portals was sketched out in organisational terms, discussions on how to proceed would always come down to technical matters. Standardisation was considered to be crucial, followed by the question of whether the data was accessible enough. The bottom line was that it was most important that the issue of technological standardisation should be settled properly. Technological matters dominated discussions:

A: Technology is not really a problem anymore. We can build everything we want without any limit. All the techniques needed are at our disposal.

B: That's right, the things that do matter are organisational aspects. Look at the US example of Geospatial One Stop. They just do it: American government agencies put everything they have on the web, without restrictions.

C: But its quality is doubtful at best, they don't guarantee its accuracy. I wonder if anybody actually uses it.

A: If we follow the example of Geospatial One Stop, then it will look like NCGI. We have to do better than that.

$\mathrm{B}$ : Just use the right standards. That is of paramount importance. The architecture we have developed is perfectly equipped to set up a network.

A: If we stick to proven technology and standards, nothing can go wrong.

$\mathrm{B}$ : But what is that, which standard is proven, which standard is commonly used, which one really works?

C: Here we go again!

In November 2005, the core team, made up of representatives of a few major participating organisations, attempted to tackle the problems experienced by calling the project team together for a two-day brainstorming session in a remote countryside hotel. The technology and standardisation issues had been declared settled, but still played a role, while the intention was to produce a strategy for developing a user-driven approach. The program for the session mentions a meeting with a public relations consultant and the question of how to bring more user-drivenness into the project. In fact, user orientation was extensively discussed, eventually leading to a 'motto' of which the team was very proud: 'Able to find and allowed to use'.

The subsequent working conference, in which the project was to be presented to the GI community in December 2005, was also a pressing issue. The project team had mixed feelings about whether there was anything tangible to demonstrate and thought that if this was not the case, it would be better to cancel the presentation. After some deliberation it was agreed that a rudimentary version of the Red Portals would be demonstrated.

Thus, in December 2005 the Geo Portals project was launched before a GI audience at the conference. The core team was determined to make a convincing statement by showing that the project was user-driven and was doing the right thing in terms of technology, but also felt a little uncertain. The audience was familiar with SGI and its projects and knew of the existence of the Geo Portals project, but was unfamiliar with the details. Sheer curiosity brought about fifty GI professionals together.

In his introduction, the scientific director of SGI signified the importance of Geo Portals for SGI, proclaiming it to be a key project. The core team then gave a presentation about the demand-drivenness of the project and elucidated the 'motto'. Despite the importance with which this was regarded by the project team, it barely raised the interest of the audience. However, the demonstration of a rudimentary version of the Red Portals website using data from the built environment had an astonishing effect. What the Geo Portals team considered window-dressing was the very thing that convinced the audience of the project's importance. In subsequent discussions it became apparent that participants were convinced that the Geo Portals project was SGI's key project and that it was technically well managed and would make a difference. The Geo Portals project team celebrated the day as a success.

\subsubsection{Narrative Setting, Space and Storyboard}

In this case, technology is the dominating factor in the narrative setting. In the past it has been an impediment with respect to infrastructure development, but in this setting this was no longer the case, the team considering it possible to apply GI technology for the disclosure of data in a way that society as a whole would benefit. In this setting, GI technology is seen as an ever-developing and changing phenomenon that will be mastered through the application of standards and result in an infrastructure with a rather static form, divided into thematically organised compartments of data that give it a neatly arranged appearance.

In the narrative space, the project team has a direct re- 
lationship with the GI community. Individual project members belong to organisations that financially support the project, but these organisations are not recognised as individual partners. As a whole, the organisations have a neutral and minor role and are all seen as equal and as supporting the common cause of sharing GI data. GI data users are recognised as a defined group through the user motto, but a clear picture of these users has still not been developed.

A storyboard emerges concerning the propensity to let technology work for the GI sector through the application of standards. The Geo Portals project is seen to be acting on behalf of the entire GI sector, detached from individual organisations and creating a stable infrastructure.

\subsection{Attempting to Reduce Uncertainty}

The project team continued its project meetings on a fixed day of the month in a centrally situated venue, with meetings held in a building occupied by one of the participating organisations. The morning agenda was devoted to management matters, while discussions prepared by a core team member or an external speaker took place in the afternoon. However, fundamental issues would emerge during the morning sessions and be discussed over lunch, sometimes continuing throughout the day, suggesting a certain level of insecurity. Nevertheless, a research paper written by the project members to convince European peers expressed confidence [91].

The Geo Portals project was meant to provide all possible kinds of data, to be delivered to both professional users and the general public. Professional users only needed disclosed data, while lay users could be provided with software services which had to be developed for integrating, harmonising and presenting data. Existing examples of the disclosure of geo data through websites were reviewed, the flaws convincing the project members that there were many difficulties involved in bringing together different sources. Services designed to harmonise and present data were seen as essential to Geo Portals, emphasising the user orientation of the project, which was communicated to the GI community. The core team developed the example of a beer brewer in need of geo information to assist in finding a location for a new brewing facility. In all the subsequent presentations and promotional material, including an SGI promotional film, this example-which connected different processes within different public organisations-was made prominent [92].

User orientation also generated interest in legal aspects and the issue of digital rights management. A researcher affiliated with Geo Portals translated an approach for regulating copyright on the internet into a model applicable to the field of geo information. This model, regulating legal and economic aspects of geo information, was regarded as essential for Geo Portals, although, however important it was felt to be, it was also seen as a separate entity, unlike technological issues. Technology was held to be dynamic, while the access model was found to be static. Further development of the model was embedded in another SGI project, placing it beyond the control of the project team.

At the end of 2006, the project team began to feel uncomfortable about the lack of steering capacity at SGI. While SGI saw Geo Portals as the core project of the program, the core team thought SGI, giving voice to the management of individual organisations, should provide an overarching framework. As SGI was seen as the custodian of the National Geo Information Infrastructure, a serious discussion among project participants was devoted to this topic:

A: We are supposed to work on NGII. For SGI, Geo Portals are considered as focal, but they don't say anything about the guidelines we should follow or how to connect to other projects that are part of the NGII.

B: They are talking about a test bed for NGII, but is NGII only a test bed? Are we supposed to deliver something that actually works?

C: We are certainly working on our data viewer, but to what standards should it comply? Are there any organisations that are going to use it?

A: They say that a new GI coordinating organisation is in the making-yet another organisation that is supposed to organise something. We need guidelines and all they do is establish a new organisation. This does not sound like coordination to me!

D: I think that as a Geo Portals team we should take a stand and do what SGI refuses: take the lead!

The core team did not feel supported by SGI, which until then had been seen as the keeper of the National Geo Information Infrastructure, of which Geo Portals was a part. At the end of 2006, SGI published an article in a leading professional magazine with the provocative title: 'Where to with the Dutch Geo Information Infrastructure?' [93]. It provoked discussion and also made the core team feel that SGI had no strategy.

Geo Portals concentrated on the work to be done: new services had to be developed with new software. Choices had to be made on what technology to use and what standards to apply. The core team, representing three government-supported knowledge institutions and a software company, felt responsible for this part of the project and took up the challenge of drawing up a framework and organising software development. A participating engineering firm also did some work, but took little part in any conceptual, organisational or management activities.

During the software development process, the core team came together on a weekly basis to coordinate software development which was undertaken by software engineers from core team member's organisations. In spring 2007, these efforts resulted in a data viewer, a software device designed to be capable of consistently retrieving geo data from different sources on a computer screen. The Geo Portals core team, being enthusiastic about it, saw it as a 
requirement for bringing the ultimate goal, a system of Geo Portals, one step closer.

While celebrating this achievement, project members soon felt that the newly developed data viewer was already becoming outdated because new techniques were now available. This gave software engineers the opportunity to develop even more sophisticated viewers. Thus, while having a tested product ready for implementation, the development process went on, with an enthusiastic core team managing the same team of software developers. While working with the newest technologies they gave the impression that these developments were quite normal for them-new technology had to be explored and applied.

\subsubsection{Narrative Setting, Space and Storyboard}

In this phase of the project, the narrative setting becomes increasingly dominated by technology. To serve lay users, services have to be developed using state-of-the-art technology. Standards are still important but they are appraised as being of lesser concern. Legal aspects are seen as a separate area that needs to be dealt with, but not necessarily by the project management team.

In the narrative space, the management of individual participating organisations is seen as collectively organised into advisory boards of the SGI program. The program itself is considered to be unsupportive, as it simply does not have a policy, and those on the boards are not seen as GI experts, but as serving the interests of individual organisations, which are not necessarily the interests of the Geo Portals project. Those involved in the Geo Portals project must recognise that in order to be successful they must plot their own course, which will be to address the newest trends in GI technology.

The storyboard at this stage is at the point of exploring the latest GI technology and incorporating this into a test website. Once the technology is ready to be used as a building block for GI infrastructure, further effort will be put into assessing newer technological improvements.

\subsection{Towards Judgement Day}

In 2007, the Geo Portals project was on track as far as software development was concerned, but the core team was becoming increasingly agitated, feeling that the initial goal of sharing geo information was moving out of reach. At the project team meeting in April 2007, a discussion on this point was initiated by two core team members in an attempt to engineer a breakthrough:

It is terribly sad that we cannot build on the achievements of SGI. It looks like management does not recognise what it is all about. In the Netherlands we have an abundance of geo data, distinguished scholars, high GIS penetration, a vast and schooled workforce and many knowledge exchange networks. Perfect circumstances for great ideas. But guess what? We just keep on chatting!

Nobody seemed to be in charge of developing the NGII, and the decision-makers at SGI were depicted as abstract thinkers with no practical knowledge. It was felt that a breakthrough was needed, and the appraisal of the SGI promotional conference held in March 2007 did not display any confidence:

A: I am sad to say that real sharing of geo information is further away than ever. We have just had the SGI conference in Rotterdam. It lacked any ambition. The bottom line was: 'The NGII has to be developed, but let's move on as we did'. That's not the way to get it done.

B: It was a convention of the same people that you see all the time at such events; 'the usual suspects' were doing their ritual thing.

C: It was like being in some religious rally, people celebrating and praising something of which everybody has a different image.

$\mathrm{B}$ : It is a paradoxical situation. When we need a breakthrough, surprise, surprise, nobody wants to change, we keep on doing things the way we did, and nothing really changes.

C: Everybody talks about the costs of an NGII, the benefits are not mentioned.

A: An NGII will add value, that's the raison d' être. If we only want an NGII for incident management and fighting terrorism we're on the wrong track.

Despite the uncertainty, Geo Portals was considered to be successful because it offered technical solutions. The technology only had to be brought to a meaningful conclusion in order to establish the NGII, but failing management seemed to obstruct this. Perceptions of the role of Geo Portals started to change:

It is perfectly clear that it was unattainable to build an infrastructure. Just look at the budget we had for this project: it was clear even before we started that it was insufficient. Our job was to deliver building blocks, to innovate for the sake of an NGII.

We are good at the technological aspects. So if they ask us for such a project, we will handle technology. Without any guidance from SGI, it is impossible to develop an NGII. What we can offer for a future NGII is best practices and software tools. We form a community for NGII development.

Another working conference was organised for November 2007 with a striking theme: 'Just do it'. External experts were asked to focus on financial, legal and organisational aspects, while Geo Portals project members were keen to present the technical aspects. The message in workshops was that new software applications, as developed by Geo Portals, were fully capable of integrating geo data from different sources. This message was symbolised using Lego blocks, representing geo data building blocks which could be put together in any possible way.

Now that the finish was in sight, the project team wanted to deliver results which could be used in the future. Slowly but steadily, the project goals were redefined. The obligation to produce tangible products changed, with the Geo Portals team coming to see itself as a 'commu- 
nity of practice'. The image of the project as developing building blocks for an NGII now changed, with Geo Portals being reconceived as a knowledge-creating project. The atmosphere also changed, from distress to optimism to euphoria, although one of the more sceptical project team members noted that what was occurring was 'expectation management'.

It was felt that the positive results should be disseminated to the GI community, for example in a research paper [94], and a new sector-wide policy coordinating organisation called Geonovum began to promote itself. While the Geo Portals project team had at first thought that this organisation was covering up the failings of the geo information sector, they now thought that Geonovum could secure the innovative achievements of Geo Portals for the future. The image of SGI changed accordingly, from being purely involved in funding to becoming a knowledge-boosting program that should be continued.

At the closing conference in December 2008 there was confidence about the results. The highest civil servant responsible for geo information in the Ministry of Housing, Spatial Planning and the Environment was the keynote speaker, addressing 150 people in a prestigious location. A specially produced video presented the improvement of the accessibility of geo information as an ongoing project, suggesting that there was much work still to be done. Software applications were presented as stepping stones in a continuous progression, invoking a great deal of interest in newly developed techniques. A new website with a new name (Carta Fabrica) was also launched, where the achievements of Geo Portals were to be made available. Both the core team and the audience were optimistic about the future.

In interviews held after the completion of the project, the image of technology as dominating all developments was persistent. Standards were seen as a thing of the past because technology was now seen as being capable of connecting all forms of data. The approach was referred to as 'Web 2.0', signifying that the new technology was obviously web-based. It was also noted by Geo Portals project members that Geonovum was still working on a National Geo Register aiming at the registration and standardisation of all governmental geo data but that this project was obsolete because Web 2.0 would solve all the connection problems where standardisation had failed. However, most importantly, the National Geo Register was seen as a project that hampered innovation in the geo information sector.

\subsubsection{Narrative Setting, Space and Storyboard}

In the narrative setting, technology is now treated as the essence of Geo Portals. Technology is seen as an unleashed phenomenon, now labelled as 'innovation', and it is ready to solve any problem, with the aim of making the world a better place. Innovation is thus seen as an enabler of dynamic geo information management, without being chained by standards. However, the solutions created by this technology are found to be obsolete before they can be used, not because they do not function properly but because they are superseded by solutions powered by even more sophisticated technology.

In the narrative space, both diverging and converging tendencies can be observed. The GI sector management, speaking through organisations such as Geonovum and SGI with their emphasis on standards, is found by Geo Portals project members to inhibit the possibilities created by the application of technology. By providing insufficient funding they are also seen as responsible for not delivering Geo Portals as originally planned. Realising that the initial goals were untenable, the Geo Portals team redirected their aim towards creating innovation to facilitate the creation of an NGII. As the SGI was supposed to stimulate innovation in geo information sharing, the Geo Portals project team felt quite comfortable with their new goals, knowing that their project would stimulate innovation.

The storyboard that can be identified here aims at the production of new technologies which could be made available to the GI sector. It affects the reframing of goals, moving from the creation of a static infrastructure into making new technologies available. This reframing is justified through concluding that the funds originally granted by SGI were inadequate to realise the GI infrastructure considered in the initial plan.

\section{Discussions}

In this paper, we have used the framework of narrative setting, space and storyboard to analyse the Geo Portals project. Three phases of the project were identified, in which the narrative setting and space could be placed in a relationship with a developing storyboard. The Geo Portals project had a clear beginning and end, and there were also some preparatory activities which were considered to be important for the analysis, as well as the impact of the project on the Dutch GI sector.

Initially, the Geo Portals project proposal was to develop an infrastructure serving societal needs. These needs were converted into user profiles with different demand structures. As project participants became dissatisfied with the lack of guidelines for an overarching strategy, they started to develop software applications. Because they considered themselves to be the vanguard of everchanging technology, the idea of building an infrastructure slowly faded. Consequently, the goal shifted towards providing a toolbox, which in turn changed into the image of the project as stimulating innovation.

The narrative setting, dominated by rapidly developing information technology, encouraged project participants to look to the future, and the Geo Portals project acted as a means to deal collectively with this task and to apply the latest technology to create newly developed software applications. Geo Portals project members, acting inde- 
pendently of their respective organisations, made new technology available, while unintentionally ensuring that no individual or organisation could be blamed for failure. Because the Geo Portals project was supposed to be beneficial to the whole GI sector, the project team decided to supply state-of-the-art technology.

In the narrative space, SGI was seen as an enabling organisation, acting on behalf of the Dutch GI community, in relation to which the Geo Portals project would be beneficial to the whole sector. The Geo Portals project team saw SGI as a temporary organisation, being part of the GI community and primarily involved in sustaining the Geo Portals concept through funding with money budgeted for the GI community. This relationship made the project team cautious, responsible and somewhat selfreflective. Thus, SGI brought the GI community together around a financing source, forcing individual organisations to cooperate with each other in order to be eligible for funding.

The analysis shows a cyclical storyboard: whenever new technology was tested and approved, newer technology was already virtually available to be tested and eventually to be confirmed as a new standard. The data shows two of these cycles, with the typical pattern being depicted in Figure 2. This is the storyboard of the action occurring within the project, which can also be interpreted as a vicious circle [95].

In a world with a pressing and increasing turnover of technological innovations, reliable infrastructures might create stability. The two competing narratives of stability and change always struggle for dominance. An infrastructure is a fixed, predictable, stable, unambiguous and ubiquitous facility that users almost take for granted [96] and a focus on the development of a standardised infrastructure utilises the narrative of stability, a prominent feature in the initial Geo Portals project proposal. The difficulties involved in standardisation were already recognised in the project's subtitle: 'liberty united' and a strict regime of standardisation was also feared, as well as being considered difficult to implement. Therefore, a limited, 'light' version of standardisation was proposed.

Throughout the project, from the initial presentation of the Red Portals, which was hailed as innovative, until the conclusion, when the entire Geo Portals project was declared innovative, the emphasis was on change. Newly developed software, already obsolete on the day of its realisation, was not considered a problem. Moreover, it was seen as essential, as the average GI professional sees tomorrow's technology as the solution to problems encountered today.

The storyboard of innovation remains prominent. The core message of SGI, to be innovative, hampered the development of an infrastructure. For this reason, the project was reframed into a knowledge-generating endeavour, driven

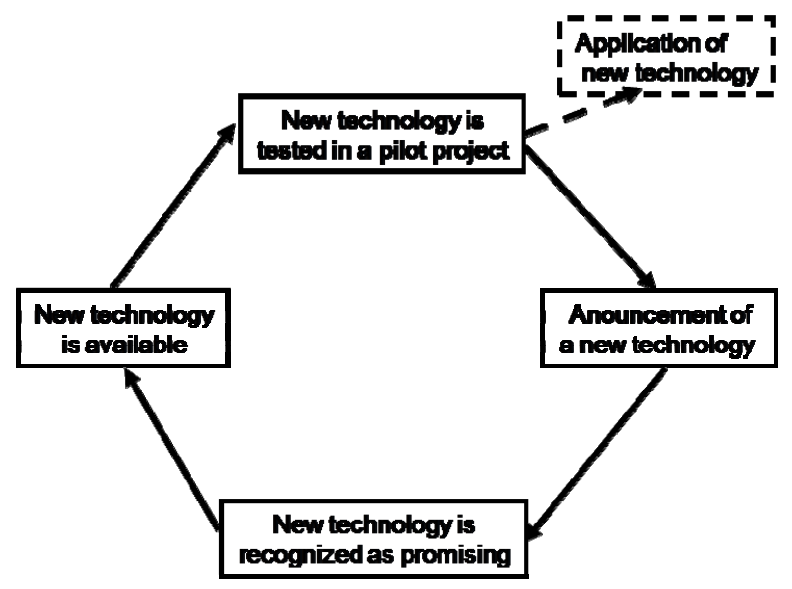

Figure 2. The storyboard of innovation

by a storyboard of innovation. Ultimately, the GI community would judge the project on its innovative qualities, presented through state-of-the-art software. While this is a tangible result of the four-year Geo Portals project, it is only temporary, with no reference to infrastructure.

\section{Conclusions}

Delivering infrastructure seems to involve two contradictory aspects [97]. On the one hand there is a narrative of change, expressing the urge to work with the newest technology, and on the other hand there is a narrative of stability which sees infrastructure as predictable and stable and thus useful. These two narratives seem to fight for attention.

As the Geo Portals program basically aimed at innovation, the narrative of change was dominant, and can be identified in the innovation storyboard. Infrastructure development rather than infrastructure building was paramount, and thus a stable, recognisable infrastructure was absent.

The narratives reflect the basic stability/change contradiction [66]. The confrontation of these two differing narratives is not uncommon and has been called the 'innovation paradox'. It is found in large public sector projects where a fixed infrastructure has to be delivered in an unstable environment [49].

It has been suggested that when problems with the construction of infrastructures emerge it is necessary to focus on project designs in the light of cultural settings [98]. However, here there was more at stake. A GI community, seemingly preoccupied with innovation, desperately required a useable infrastructure. While one of those involved in the project suggested that infrastructures are always in a process of innovation and should be regarded as 'moving targets', in order to be used, infrastructures also need to be stable. Thus, the sector as a whole must find equilibrium between stability and change in relation to infrastructure. Now that these driving forces have been identified, a breakthrough is within reach. 


\section{REFERENCES}

[1] J. Crompvoets, "National spatial data clearinghouses, worldwide development and impact,” Wageningen Universiteit, Wageningen, 2006.

[2] A. Rajabifard and I. Williamson, "Spatial data infrastructures: Concept, sdi hierarchy and future directions," Geomatics 80, Tehran, Iran, 2001.

[3] D. Nebert, “The SDI cookbook,” 2004. http://www. gsdi. org/pubs/cookbook/

[4] F. de Bree and A. Rajabifard, "Involving users in the process of using and sharing geo-information within the context of SDI initiatives," Pharaohs to Geoinformatics, FIG Working week, 2005.

[5] I. Masser, "GIS worlds: Creating spatial data infrastructures,” ESRI Press, Redlands CA, 2005.

[6] Y. Georgiadou, S. K. Puri, and S. Sahay, "Towards a potential research agenda to guide the implementation of Spatial Data Infrastructures: A case study from India," International Journal of Geographical Information Science, Vol. 19, No. 10, pp. 1113-1130, 2005.

[7] J. Crompvoets et al. eds, "A multi-view framework to assess SDIs,” Space for Geo-Information (RGI), Wageningen University and Centre for SDIs and Land Administration, Department of Geomatics, University of Melbourne, Melbourne, Australia, 2008.

[8] H. Koerten, "Assessing the organisational aspects of SDI: Metaphors matter," A Multi-View Framework to Assess SDIs, J. Crompvoets et al., Editors, Melbourne, pp. 235254, 2008.

[9] Y. Georgiadou, O. Rodriguez-Pabón, and K. Lance, "Spatial data infrastructure (SDI) and e-governance: A quest for appropriate evaluation approaches," URISA Journal, Vol. 18, No. 2, pp. 43-55, 2006.

[10] W. van den Toorn and E. de Man, “Anticipating cultural factors of GDI,” in Geospatial data infrastructure: Concepts, cases and good practice, R. Groot and J. McLauglin, Editors, Oxford University Press, Oxford, 2000.

[11] E. de Man, "Cultural and institutional conditions for using geographic information: Access and participation," URISA Journal, Vol. 15(APA I), pp. 29-33, 2003.

[12] H. Koerten, "Blazing the trail or follow the Yellow Brick Road? On geo-information and organizing theory in GI days,” Young researchers Forum, 10-12 September 2007, F. Probst and C. Kessler, Editors, Institut für Geo-informatik, Universität Münster: Münster, Germany, pp. 85104, 2007.

[13] D. Hodgson and S. Cicmil, eds., "Making projects critical,” in Management, Work and Organisations, Palgrave Macmillan, New York, 2006.

[14] A. van Marrewijk and M. Veenswijk, "The culture of project management: Understanding daily life in complex megaprojects,” Pearson Education Limited, Harlow, UK, 2006.

[15] H. Blumer, "Symbolic interactionism, perspective and method,” Prentice Hall, Englewood Cliffs ,NY, 1969.

[16] G. Ritzer, "Modern sociological theory," Mc Graw-Hill International Editions, NY, 1996.
[17] E. Goffman, “The presentation of self in everyday life,” Doubleday Garden City, NY, 1959.

[18] G. Goffman, "Frame analysis,” Harper \& Row, NY, 1974.

[19] G. Gonos, “'Situation' versus 'Frame': The 'Interactionist' and the 'Structuralist' analysis of everyday life,” American Sociological Review, Vol. 42, pp. 854-867, 1977.

[20] P. Manning, "Erving Goffman and modern sociology", Stanford University Press, Stanford CA, 1992.

[21] J. Habermas, “The theory of communicative action,” Lifeworld and System, Beacon Press, Boston MA, Vol. 2, 1987.

[22] A. Giddens, "Modernity and self-identity: Self and modernity in the late modern age," Stanford University Press, Stanford CA, 1991.

[23] U. Beck, “Risk society,” Sage Publications, Newbury Park, California, 1992.

[24] G. Ritzer ed., "The McDonaldization of society revised edition,” Pine Forge Press, Thousand Oaks CA, 1996.

[25] A. Giddens, "Central problems in social theory: Action, structure and contradiction in social analysis," Basingstoke, MacMillan, 1979.

[26] M. Archer, "Culture and agency: The place of culture in social theory,” Cambridge University Press, Cambridge, 1988.

[27] P. Bourdieu and D. Pels, "Opstellen over smaak, habitus en het veldbegrip,” Van Gennep, Amsterdam, 1989.

[28] P. L. Berger and T. Luckmann, "The social construction of reality,” Penguin Books, Harmondsworth, 1967.

[29] K. Gergen, "Realities and relationships, soundings in social construction,” Harvard University Press, Cambridge MA, 1994.

[30] D. Boje, "Stories of the storytelling organization: A postmodern analysis of Disney as 'Tamara-Land'," Academy of Management Journal, Vol. 38, No. 4, pp. 997-1035, 1995.

[31] M. Berendse, H. Duijnhoven, and M. Veenswijk, “Editing narratives of change, identity and legitimacy in complex innovative infrastructure organizations," Intervention Research, pp. 73-89, 2006.

[32] D. Polkinghorne, "Narrative knowing and the human sciences,” State University of New York Press, NY, 1988.

[33] M. Hatch and D. Yanow, "Organization theory as an interpretive science," The Oxford Handbook of Organizational Theory, C. Knudsen and H. Tsoukas, Editors, Oxford University Press, Oxford, UK, 2003.

[34] K. Verduijn, "Tales of entrepreneurship, contributions to understanding entrepreneurial life,” $\mathrm{PhD}$ thesis Vrije Universiteit Amsterdam, Amsterdam, 2007.

[35] P. Ricoeur, “The model of the text: Meaningful action considered as text”, New Literary Society, Vol. 5, pp. 91120, 1973.

[36] C. Oswick, T. Keenoy, and D. Grant, "Discourse, organizations and organizing: Concepts, objects and subjects," Human Relations, Vol. 53, No. 9, pp. 1115-1124, 2000.

[37] D. Grant, et al., eds, "Introduction: Organizational discourse: Exploring the field,” The Sage Handbook of Organizational Discourse, Sage Publications Inc, Thousand Oaks CA, pp. 1-36, 2004. 
[38] D. Grant, T. Keenoy and C. Oswick, eds, "Discourse + Organization,” Sage Publications Ltd, London, UK, 1998.

[39] N. Frye, “Anatomy of criticism: Four essays," Princeton University Press, Princeton, NJ, 1957.

[40] K. Burke, “A grammar of motives,” University of California Press, Berkeley and Los Angeles, 1969.

[41] K. Gergen, “An invitation to social construction,” Sage, London, 1999.

[42] Y. Gabriel, "Storytelling in organizations, facts, fictions, and fantasies,” Oxford University Press, Oxford, UK, 2000.

[43] T. Peters and R. Waterman, "In search of excellence, lessons from America's best-run companies," Harper \& Row, New York, 1982.

[44] S. Helmers and R. Buhr, "Corporate story-telling: The buxomly secretary, a pyrric victory of the male mind," Scandinavian Journal of Management, Vol. 10, No. 2, pp. 175191, 1994.

[45] E. Schein, "Culture: The missing concept in organization studies,” Administrative Science Quarterly, Vol. 41, No. 2, pp. 229-240, 1996.

[46] J. Brown, et al., "Storytelling in organizations: Why storytelling is transforming 21st century organizations and management,” Butterworth-Heinemann, Burlington MA, 2005.

[47] A. Brown, P. Stacey, and J. Nandhakumar, "Making sense of sensemaking narratives”, Human Relations, Vol. 6, No. 8, pp. 1035-1062, 2008.

[48] K. E. Weick, “Sensemaking in organizations”, Sage Publications, London, 1995.

[49] M. Veenswijk, "Surviving the innovation paradox: The case of Megaproject X," The Innovation Journal, The Public sector Innovation Journal, Vol. 11, pp. 2, article 6, pp. 1-14, 2006.

[50] J. Bruner, "The narrative construction of reality," Critical Inquiry, Vol. 18, pp. 1-21, 1991.

[51] M. Alvesson and D. Karreman, "Variety of discourse: On the study of organizations through discourse analysis," Human Relations, Vol. 53, No. 9, pp. 1125-1149, 2000.

[52] C. Kohler Riessman, "Narrative analysis," Sage Publications, Newbury Park CA, Vol. 30, 1993.

[53] B. Czarniawska-Joerges, "A narrative approach to organization studies," Sage Publications Inc, Thousand Oaks CA, Vol. 43, 1998.

[54] D. Yanow, “Conducting interpretive policy research," Sage Publications Inc, Thousand Oaks CA, 2000.

[55] D. Boje, "Narrative methods for organizational and communication research", Sage Publications Ltd, London, 2001.

[56] S. Tesselaar, I. Sabelis, and B. Ligtvoet, "Digesting stories: About the use of storytelling in a context of organizational change," in 8th International Conference on Organizational Discourse 2008, London, UK, 2008.

[57] N. Beech and C. Huxham, "Cycles of identity formation in inter-organizational collaborations," International Studies of Management \& Organization, Vol. 33, No. 3, pp. 28-52, 2003.

[58] T. Deal and A. Kennedy, "Corporate cultures: The rites and rituals of corporate life,” Penguin, 1982.
[59] H. Bergson, "The creative mind," Greenwood Press, Westport CT, 1946

[60] G. Burrell, "Back to the future: Time and organization, in rethinking organization, new directions in organization theory and analysis,” M. Reed and M. Hughes, Editors, Sage Publications Ltd, London, UK, pp. 165-183, 1992.

[61] G. Burrell, “Time and talk,” Organization, Vol. 7, No. 3, pp. 371-372, 2000.

[62] R. Chia, "Essay: Time, duration and simultaneity: Rethinking and change in organizational analysis," Organization Studies, Vol. 23, No. 6, pp. 863-868, 2002.

[63] M. Heidegger, "Sein und zeit [Being and time],” Tübingen D, Max Niemeyer, 1977.

[64] B. Czarniawska-Joerges and G. Sevón, eds, “Translating organizational change,” ed. A. Kieser, de Gruyter Studies in Organization, Walter de Gruyter, Berlin, Germany, Vol. 56, 1996.

[65] E. Schein, "Organizational culture and leadership,” Jossey Bass, 2nd Edition, 1992.

[66] M. Douglas, "How institutions think”, Syracuse University Press, Syracuse, 1986.

[67] S. Chreim, "The continuity-change duality in narrative texts of organizational identity,” Journal of Management Studies, Vol. 42, No. 3, pp. 567-593, 2005.

[68] R. Harré, "Life sentences, aspects of the social role of language,” John Wiley \& Sons, London, UK, 1976.

[69] H. Lefebvre, “The production of space,” Blackwell Publishers, Oxford, UK, 1991.

[70] W. R. Scott, "Institutions and organizations,” Sage Publications, 1995.

[71] D. Yanow, "Built space as story: The policy stories that buildings tell,” Policy Studies Journal, Vol. 23, No. 3, pp. 407-422, 1995.

[72] D. Yanow, "How built spaces mean, in interpretation and method: Empirical research methods and the interpretive turn,” D. Yanow and P. Schwartz, Editors, M. E. Scharpe, Armonk NY, 2006.

[73] M. Gastelaars, "Talking stuff: What do buildings tell us about an organization's state of affairs?” in 8th International Conference on Organizational Discourse, London, UK, 2008.

[74] B. Schneider, “The people make the place," Personnel Psychology, pp. 437-453, 1987.

[75] W. Orlikowski, "Using technology and constituting structures: A practice lens for studying technology in organizations,” Organization Science, Vol. 11, No. 4, pp. 404428, 2000

[76] W. Bijker, "Of bicycles, bakelites, and bulbs, towards a theory of sociotechnical change," The MIT Press, Cambridge, 1995.

[77] W. Orlikowski, "Sociomaterial practices: Exploring technology at work," Organization Studies, Vol. 28, No. 9, pp. 1435-1448, 2007.

[78] M. Lipsky, "Street-level bureaucracy: Dilemmas of the individual in public services,” Russell Sage Foundation, New York, 1980 
[79] S. Barley, "The alignment of technology and structure through roles and networks," Administrative Science Quarterly, Vol. 35, pp. 61-103, 1990.

[80] J. Bartunek, "The importance of contradictions in social interventions," Intervention Research, Vol. 1, pp. 103113, 2004.

[81] S. Ybema, "Constructing collective identity: Central, distinctive and enduring characteristics?” in 8th International Conference on Organizational Discourse, London, UK, 2008.

[82] H. Garfinkel, "Studies in ethnomethodology,” Polity Press, Cambridge, 1984.

[83] E. Wenger, "Communities of practice: Learning, meaning and identity,” Cambridge University Press, Cambridge, UK, 1998.

[84] B. Latour and S. Woolgar, "Laboratory life: The construction of scientific facts,” Princeton University Press, 1986.

[85] K. Golden-Biddle and K. Locke, "Appealing work: An investigation of how ethnographic texts convince”, Organization Science, Vol. 4, No. 4, pp. 595-616, 1993.

[86] H. Duijnhoven, "Tales of Security practices within Spanish and Dutch railway operators: Translation, transformation or transgression?” in 8th International Conference on Organizational Discourse, London, UK, 2008.

[87] T. Watson, "Ethnographic fiction science: Making sense of managerial work and organizational research processes with Caroline and Terry," Organization, Vol. 7, No. 3, pp. 489-510, 2000.

[88] RAVI, "Space for geo-information BSIK knowledge project proposal,” RAVI, Amersfoort, 2003.

[89] A. Schmidt and G. Nieuwenhuis, “Geoportals 'Liberty
United'," Project proposal for space for geo information, Wageningen, 2002.

[90] M. Hoogerwerf and B. Vermeij, "Geoportal framework version 0.2,” (Geoloketten Raamwerk versie 0.2), 2005.

[91] J. Zevenbergen et al., "Connecting the Dutch geo-information network-liberty united,” UDMS, Aalborg, Denmark, 2006.

[92] D. van de Laak, “DVD: Alles draait om geo,” Ruimte voor Geo-Informatie, Netherlands, 2007.

[93] A. Bregt and J. Meerkerk, "Waarheen met de nationale geo-informatie infrastructuur?” Geo-Info, Vol. 7/8, pp. 296-301, 2006.

[94] J. Zevenbergen, et al., “'Geoportal Network’: More process catalyst than project," UDMS, Ljubljana, Slovenia, 2009.

[95] M. Masuch, "Vicious circles in organizations," Administrative Science Quarterly, Vol. 30, No. 1, pp. 14-33, 1985.

[96] P. Edwards, et al., "Understanding infrastructure: Dynamics, tensions, and design,” Report of a Workshop on "History \& theory of infrastructure: Lessons for new scientific cyberinfrastructures,” 2007.

[97] O. Hanseth, E. Monteiro, and M. Hatling, "Developing information infrastructure: The tension between standardization and flexibility," Science, Technology \& Human Values, Vol. 21, No. 4, pp. 407-426, 1996.

[98] A. van Marrewijk, et al., "Managing public-private megaprojects: Paradoxes, complexity, and project design,” International Journal of Project Management, Vol. 26, pp. 591-600, 2008. 